\title{
Determining Risk Factors of Postoperative Delirium in Patients Undergoing Liver Transplantation [Letter]
}

This article was published in the following Dove Press journal: Neuropsychiatric Disease and Treatment

\section{Zhao-jing Xue \\ Yi Cheng \\ Fu-Shan Xue (iD)}

Department of Anesthesiology, Beijing Friendship Hospital, Capital Medical University, Beijing, People's Republic of China
Correspondence: Fu-Shan Xue Department of Anesthesiology, Beijing Friendship Hospital, Capital Medical University, NO. 95 Yong-An Road, XiCheng District, Beijing 100050, People's Republic of China

Tel +86- |39| II 77655

Fax +86-I0-63I38362

Email xuefushan@aliyun.com

\section{Dear editor}

In the recent article of $\mathrm{Chen}_{\mathrm{et}} \mathrm{al}^{1}$ determining the risk factors for postoperative delirium (POD) in patients undergoing liver transplantation, the multivariate logistic regression analysis showed that preoperative ammonia $\geq 46 \mu \mathrm{mol} / \mathrm{L}$, Model for End-Stage Liver Disease score $\geq 15$, hepatic encephalopathy, anhepatic period, and aspartate aminotransferase at the first postoperative day were the independent risk factors for POD. The findings of this study have potential clinical implications, but there are several issues in methodology that need further clarification.

First, the authors describe that two doctors independently diagnosed POD using the Confusion Assessment Method for the ICU. It was unclear whether all of POD assessments were performed in the ICU. In fact, this tool should be used daily on all patients admitted to the ICU even if they are mechanically ventilated. For nonventilated patients in the surgical ward, the Confusion Assessment Method is more appropriate tool for POD evaluation. ${ }^{2}$ Most importantly, the readers were not provided with the duration of POD assessment and definitions of POD. The 2018 newest recommendations for neurocognitive change associated with anesthesia and surgery suggest reporting on the occurrence of POD during hospital stay up to 1 week after surgery or until discharge and require that definitions of POD must meet the diagnostic criteria of delirium in the DSM- $5 .{ }^{3}$ We are concerned that the use of inappropriate assessment tool, non-recognized diagnostic criteria and a short assessment time to define POD would have confounded the incidence of POD reported in this study.

Second, regarding statistical analysis, the authors stated that the univariate factors with a $\mathrm{P}<0.1$ were included in the multivariate analysis. However, the detailed results of univariate analysis were not provided. In fact, establishment of a multivariate model includes three steps: a) initial comparison of demographic and perioperative variables between patients with and without POD, as described in Tables 1 to 4 of Chen et al article; ${ }^{1}$ b) incorporation of the variables with statistical significance in initial comparison, defined as $\mathrm{P}<0.05$, into the univariate analysis to examine multicollinearity among candidate independent factors; c) inclusion of the variables with large $\mathrm{P}$ values $(\mathrm{P}<0.1$ or 0.2$)$ in the univariate analysis into the multivariate model to identify the independent risk factors of POD, with their P-values, adjusted odds ratios and $95 \%$ confidence intervals. ${ }^{4}$ Due to the lack of 
multicollinearity among candidate independent variables by the univariate analysis, their results of the multivariate logistic regression analysis would be subject to bias. Furthermore, another potential bias in the study by Chen et $\mathrm{al}^{1}$ is the large number of variables studied in relation to the number of subjects included. In this case, the model built by them is probably highly overfitted.

Third, this study demonstrated that median onset and duration of POD were 2 days (Q25, Q75; 1, 3) and 5 days (Q25, Q75; 3, 7), respectively. We are very interested in knowing why other complications besides POD in early postoperative period were not observed at the same time and taken into the multivariate model for adjustment of confounders. It has been shown that early postoperative sepsis, intra-abdominal infection, renal failure, and reintubation are significantly associated with an increased risk of POD after liver transplantation. ${ }^{5,6}$ We argue that not taking postoperative factors associated with POD into the model would further have distorted with the inferences of the multivariate analysis when determining the independent risk factors of POD in this study.

Finally, this study assessed the contribution of POD to postoperative outcomes including intubation time, length of ICU or hospital stay and medical cost. Because there were significant differences between patients with and without POD in many demographic and perioperative variables affecting postoperative outcomes, however, directly comparing postoperative outcomes between them only has a limited clinical value. To determine real contribution of POD to postoperative outcomes, the authors should apply the multivariate analysis to adjust patients' demographic and perioperative data and control selection biases.

We believe that addressing the above issues will further improve transparency of this study and avoid any misinterpretation of their findings.

\section{Acknowledgment}

All authors have no financial support and potential conflicts of interest for this work.

\section{Author Contributions}

All authors contributed to data analysis, drafting or revising the article, have agreed on the journal to which the article will be submitted, gave final approval of the version to be published, and agree to be accountable for all aspects of the work.

\section{Disclosure}

The authors report no conflicts of interest in this communication.

\section{References}

1. Chen J, Wang H, He Z, et al. Analysis of risk factors for postoperative delirium after liver transplantation. Neuropsychiatr Dis Treat. 2020;16:1645-1652. doi:10.2147/NDT.S254920

2. Neufeld KJ, Hayat MJ, Coughlin JM, et al. Evaluation of two intensive care delirium screening tools for non-critically ill hospitalized patients. Psychosomatics. 2011;52(2):133-140. doi:10.1016/j.psym.2010.12.018

3. Evered L, Silbert B, Knopman DS, et al. Nomenclature consensus working group. Recommendations for the nomenclature of cognitive change associated with anaesthesia and surgery-2018. Anesthesiology. 2018;129 (5):872-879. doi:10.1097/ALN.0000000000002334

4. Arumugam SK, Mudali I, Strandvik G, et al. Risk factors for ventilator-associated pneumonia in trauma patients: a descriptive analysis. World J Emerg Med. 2018;9(3):203-210. doi:10.5847/wjem. j.1920-8642.2018.03.007

5. Tavabie OD, Colwill M, Adamson R, et al. A 'real-world' analysis of risk factors for post liver transplant delirium and the effect on length of stay. Eur J Gastroenterol Hepatol. 2020;32(10):1373-1380. doi:10. 1097/MEG.0000000000001661.

6. Lee H, Oh SY, Yu JH, et al. Risk factors of postoperative delirium in the intensive care unit after liver transplantation. World $J$ Surg. 2018;42:2992-2999. doi:10.1007/s00268-018-4563-4

\begin{abstract}
Dove Medical Press encourages responsible, free and frank academic debate. The content of the Neuropsychiatric Disease and Treatment 'letters to the editor' section does not necessarily represent the views of Dove Medical Press, its officers, agents, employees, related entities or the Neuropsychiatric Disease and Treatment editors. While all reasonable steps have been taken to confirm the content of each letter, Dove Medical Press accepts no liability in respect of the content of any letter, nor is it responsible for the content and accuracy of any letter to the editor.
\end{abstract}

\section{Publish your work in this journal}

Neuropsychiatric Disease and Treatment is an international, peerreviewed journal of clinical therapeutics and pharmacology focusing on concise rapid reporting of clinical or pre-clinical studies on a range of neuropsychiatric and neurological disorders. This journal is indexed on PubMed Central, the 'PsycINFO' database and CAS, and is the official journal of The International Neuropsychiatric Association (INA). The manuscript management system is completely online and includes a very quick and fair peer-review system, which is all easy to use. Visit http://www.dovepress.com/testimonials.php to read real quotes from published authors. 